\title{
Lipids and carotid plaque in the Northern Manhattan Study (NOMAS)
}

\author{
Hannah Gardener*1, David Della Morte1, Mitchell SV Elkind², \\ Ralph L Sacco ${ }^{1,3,4}$ and Tatjana Rundek ${ }^{1}$
}

Address: ${ }^{1}$ Department of Neurology, Miller School of Medicine, University of Miami, USA, ${ }^{2}$ Division of Stroke, Department of Neurology, Columbia University, New York, NY, USA, ${ }^{3}$ Department of Epidemiology, Miller School of Medicine, University of Miami, Miami, FL, USA and ${ }^{4}$ Department of Human Genetics, Miller School of Medicine, University of Miami, Miami, FL, USA

Email: Hannah Gardener* - hgardener@med.miami.edu; David Della Morte - dmorte@med.miami.edu;

Mitchell SV Elkind - mse13@columbia.edu; Ralph L Sacco - rsacco@med.miami.edu; Tatjana Rundek - trundek@med.miami.edu

* Corresponding author

Published: 22 December 2009

BMC Cardiovascular Disorders 2009, 9:55 doi:10.1 |86/|47|-226|-9-55

Received: 10 June 2009

Accepted: 22 December 2009

This article is available from: http://www.biomedcentral.com/I47I-226I/9/55

(C) 2009 Gardener et al; licensee BioMed Central Ltd.

This is an Open Access article distributed under the terms of the Creative Commons Attribution License (http://creativecommons.org/licenses/by/2.0), which permits unrestricted use, distribution, and reproduction in any medium, provided the original work is properly cited.

\section{Abstract}

Background: Lipids, particularly low-density (LDL) and high-density (HDL) lipoproteins, are associated with increased risk of stroke and cardiovascular disease, probably due to atherosclerosis. The objective of this cross-sectional analysis was to investigate the relation between blood lipids and carotid plaque.

Methods: As part of a prospective population-based study to determine the incidence and risk factors of stroke in a multiethnic population, we evaluated 1804 participants with lipid measurements and B-mode ultrasound of carotid arteries (mean age $69+/$ - 10 years; $40 \%$ men; $51 \%$ Hispanic, $26 \%$ black, $23 \%$ white). The association between lipid parameters and carotid plaque was analyzed by multiple logistic regression.

Results: Plaque was present in $61 \%$ of participants. Mean total cholesterol was $202+/-41 \mathrm{mg} / \mathrm{dl}$. After controlling for other lipid parameters, demographics, and risk factors, the only cholesterol subfraction associated with carotid plaque was LDL (OR per standard deviation $(S D)=1.14,95 \%$ $\mathrm{Cl}$ 1.02-1.27). Neither HDL nor triglycerides independently predicted carotid plaque. Apolipoprotein B (ApoB) was also associated with risk of plaque (OR per SD = 1.29, 95\% Cl I.03I.60). Apolipoprotein A-I (apoA-I) was associated with a decrease in multiple plaques (OR per SD $=0.76,95 \% \mathrm{Cl} 0.60-0.97$ ), while lipoprotein a was associated with an increased risk of multiple plaques (OR per SD $=1.31,95 \% \mathrm{Cl}$ I.03-I.66). ApoB:ApoA-I had the strongest relation with carotid plaque (OR per SD = 1.35, 95\% Cl I.08-1.69).

Conclusions: Among the common lipid parameters, LDL has the strongest relation with carotid plaque. Other lipid precursor proteins such as ApoB and ApoA-I may be stronger predictors of subclinical atherosclerosis, however, and better targets for treatment to reduce plaque formation and risk of cerebrovascular disease. 


\section{Background}

Blood lipids levels, particularly elevated low-density lipoprotein (LDL) and decreased high-density lipoprotein (HDL), have been definitely associated with an increased risk of cardiovascular disease (CVD) and less clearly associated with stroke [1-4]. While there are several possible mechanisms underlying the association of lipids and stroke [5-7], one of the most important is probably the effects of lipids on the formation of carotid artery atherosclerotic plaque [8].

Although the protective effect of lipid-lowering medication on CVD and stroke risk is well-established $[4,9,10]$, data regarding the relative importance of the various lipid parameters, total cholesterol (T-CHOL), LDL, HDL, nonHDL cholesterol, triglycerides (TG), lipoprotein a (Lp(a)), apolipoprotein (Apo) B and A-I, to CVD and stroke risk is inconclusive. A large prospective cohort study of women indicated a significantly elevated risk of first cardiovascular events, including ischemic stroke, among those at the extreme quintiles of all lipid parameters, including ApoAI and ApoB, the major protein constituents of HDL and LDL, respectively. The most predictive parameters were non-HDL, HDL, and ApoB, and the lipid ratios were even more predictive, particularly T-CHOL:HDL [1]. Information regarding the association between lipid parameters and plaque formation is also limited, particularly in racially diverse populations.

While it has been suggested that ApoB and ApoA-I may play a more influential role in CVD prevention than total LDL and HDL, further research is needed to understand the optimal indicators of effective lipid-lowering treatment in patients at risk for stroke. The goal of this population-based study is to elucidate the relation between lipid levels and carotid plaque presence in a multi-ethnic cohort. Due to the complexity of lipid effects on atherosclerosis we hypothesize that the ratio of lipid parameters, rather than single lipid parameters, will be most associated with carotid plaque phenotypes. The association between lipid parameters, including lipid ratios, and various cardiovascular outcomes has been well-studied. However, research among Hispanic populations is lacking and is particularly important due to the growing population of Hispanics in the United States and the perception of evidence for a Hispanic paradox, which suggests that Hispanics have better cardiovascular health than what would be predicted based on their vascular risk factor profile.

\section{Methods \\ Subjects}

The Northern Manhattan Study (NOMAS) is a prospective, population-based, cohort study documenting stroke incidence, risk factors, and prognosis in a multiethnic urban community. Based in northern Manhattan, an area of approximately 260,000 people with 104,000 over age 39 in 1990 , this study population has a unique race/ethnic distribution that is over $50 \%$ Hispanic. Methodology for NOMAS has been described previously [11].

A total of 3298 subjects were recruited and enrolled from 1993-2001. Eligible participants (1) had never been diagnosed with an ischemic stroke, (2) were $\geq 40$ years old, and (3) resided for at least three months in a household with a telephone in northern Manhattan. Subjects were identified by random-digit dialing, and interviews were conducted by trained bilingual interviewers [12]. This study was approved by the University of Miami institutional review board, and written consent was obtained.

Subjects were recruited from the telephone sample to have an in-person baseline interview and assessment. The enrollment response rate was 75\%. Standardized questions were adapted from the validated Centers for Disease Control and Prevention Behavioral Risk Factor Surveillance System $[13,14]$.

\section{Exposure Assessment}

Blood samples were drawn after an overnight fast. Plasma levels of cholesterol and triglycerides were measured using standardized enzymatic procedures with a Hitachi 705 automated spectrophotometer (Boehringer Mannheim, Mannheim, Germany). HDL was measured after precipitation of plasma apo B-containing lipoproteins with phosphotungstic acid. LDL was calculated using the Friedewald et al. equation [15]. The inter-assay coefficients of variation in our laboratory were $2 \%$ for T-CHOL, $4 \%$ for triglycerides, and 3\% for HDL [16]. In addition to T-CHOL and its subfractions, serum levels of the LDL and HDL constituents, ApoB and ApoA-I, were also collected by commercially available immunonephelometric procedures. The interassay coefficients of variation for these measurements were 3-5\% [17]. Lp(a) levels were determined using a rate nephelometric assay (Beckman Instruments, Brea, CA) adapted for use on a Beckman Array 360 nephelometer, as described previously $[17,18]$. Lp(a) antibody was obtained from Dako Chemicals (Carpinteria, CA), and $\operatorname{Lp}(\mathrm{a})$ standards were purchased from International Enzymes (Fallbrook, CA). These standards have been standardized against the Northwest Research Lipid Laboratories (Seattle, WA). This assay had coefficients of variation of $4 \%$ and $8 \%$ at $\operatorname{Lp}(\mathrm{a})$ levels of 48 and $8 \mathrm{mg} / \mathrm{dl}$, respectively.

\section{Outcome Assessment}

Carotid artery plaque presence was assessed by high-resolution B-mode ultrasound using a GE LogIQ 700 system with a multifrequency 9 to $13 \mathrm{MHz}$ linear-array transducer. Carotid ultrasounds were performed according to standard scanning and reading protocols by trained and 
certified technologists as detailed previously [19-21]. Left and right carotid bifurcations and internal and common carotid arteries were examined for plaque presence. Plaque was defined as an area of focal wall thickening $50 \%$ greater than surrounding wall thickness confirmed by marking and comparing plaque thickness with that of the surrounding wall during scanning by electronic calipers. The plaque boundaries were traced manually from the digitized multiangled images. Maximum carotid plaque thickness (MCPT, millimeters) was measured at the peak plaque prominence from any of the three carotid artery segments using a semi-automatic IMAGE-Pro V.5.2 software (Microsoft). The intraclass correlation coefficients for within and between reader variability of plaque thickness measurements were 0.94 and 0.77 , respectively $(\mathrm{n}=88)$ [22]. Plaque surface characteristics (regular, irregular) were also recorded, and intra- and interrater correlations of plaque surface characteristics were greater than 0.90 in our laboratory.

The primary outcome of interest was any plaque presence, and secondary outcomes were (1) MCPT $>1.9 \mathrm{~mm},(2)$ more than one plaque in the carotid arteries, and (3) irregular plaque. Each of these outcomes was compared to the lack of plaque as the reference. A MCPT cutoff of $1.9 \mathrm{~mm}$ was used because it was previously shown to be predictive of cardiovascular events in this study population [23].

\section{Covariates}

Covariates in multivariate analyses included demographic and vascular risk factors measured at baseline. Hypertension was defined as a self-reported history of hypertension or a measured systolic blood pressure $\geq 140$ or diastolic blood pressure $\geq 90 \mathrm{mmHg}$. Diabetes was defined as selfreport of such history or a fasting blood sugar $\geq 126 \mathrm{mg} /$ dL. Body mass index (BMI) was measured continuously as $\mathrm{kg} / \mathrm{m}^{2}$. Pipe and cigar smoking was assessed by self-report and categorized as current (within one year), former, and never smoker. Cigarette smoking was also assessed by selfreport and defined in pack-years. Moderate alcohol use was defined as current drinking of $>1$ drink per month and $\leq 2$ drinks per day. Leisure-time/recreation physical activity was assessed by a questionnaire [24]. Moderate to heavy physical activity level was defined as engaging in one or more of selected rigorous physical activities in a typical 14-day period. Race and ethnicity were defined by self-identification based on a series of interview questions modeled after the US census and was categorized as Hispanic, non-Hispanic white, and non-Hispanic black. Individuals of other race/ethnicity were excluded.

\section{Statistical Analyses}

The following lipid levels were assessed continuously, as the primary exposures of interest: T-CHOL, HDL, LDL, TG, non-HDL (T-CHOL-HDL), ApoB, ApoA-I, and Lp(a).
The following lipid ratios were also calculated and assessed continuously: T-CHOL:HDL, LDL:HDL, and ApoB:ApoA-I. Independent samples t-tests were conducted as univariate analyses to compare the lipid parameters among those with each of the plaque outcome criteria vs. those with no carotid plaque.

Multiple logistic regression analyses were conducted to examine the association between lipid parameters and plaque outcomes, controlling for other pertinent lipid parameters, demographics (age, sex, race/ethnicity), vascular and lifestyle risk factors (hypertension, diabetes, BMI, pipe or cigar smoking, pack-years of cigarette smoking, moderate alcohol use, moderate-to-heavy physical activity), and the change in time between lipid and plaque measurements.

Analyses of LDL, HDL, and triglycerides were mutually adjusted for each other; Non-HDL was adjusted for HDL; Lp(a) and ApoB were adjusted for HDL and triglycerides; ApoA-I was adjusted for LDL and triglycerides. For all lipid parameters the odds ratios (OR) and 95\% confidence intervals (CI) are reported for a 1 standard deviation (SD) increase.

We explored potential heterogeneity by race/ethnicity, sex, and age in the association between total cholesterol and its subfractions with presence of plaque by adding interaction terms in the multivariate analyses.

The total number of individuals with measurements of both carotid plaque and T-CHOL and its subfractions (LDL, HDL, triglycerides) was 2341, from which 537 were excluded because their carotid ultrasounds were conducted more than a year prior to their blood lipid measurements. Therefore, the total sample size for this study was 1804, of which 568 had measurement of ApoB and ApoA-I and 582 had Lp(a). Only 3\% of the study population had missing covariate data.

\section{Results}

Plaque was present in $61 \%$ of participants $(\mathrm{N}=1106)$, of whom 211 (19\%) had irregular plaque, 727 (66\%) had multiple plaques, and $514(46 \%)$ had MCPT $>1.9 \mathrm{~mm}$. Plaque was observed most commonly in the internal carotid artery and bifurcation $(\mathrm{N}=1093,99 \%$ of those with plaque), and less frequently in the common carotid artery $(\mathrm{N}=123,11 \%$ of those with plaque).

Table 1 shows the characteristics of the study population, overall and stratified by plaque presence. Twenty-two percent had LDL $<100,33 \%$ had LDL 100-130, 27\% 130160 , and $17 \%>160 \mathrm{mg} / \mathrm{dl}$. Thirty-one percent had HDL levels $<40,32 \%$ had HDL between 40-50, and 36\% >50 $\mathrm{mg} / \mathrm{dl}$. Only $13 \%$ of the study population reported taking 
Table I: Characteristics of the study population: overall and by plaque presence

\begin{tabular}{|c|c|c|c|}
\hline & Overall $(N=1804)$ & No plaque $(\mathbf{N}=698)$ & Plaque $(\mathrm{N}=1 / 06)$ \\
\hline \multicolumn{4}{|l|}{ Covariates } \\
\hline Age (Mean \pm SD) & $68.5 \pm 10.1$ & $64.5 \pm 9.6$ & $71.1 \pm 9.5^{a}$ \\
\hline Male sex (\%) & 39.8 & 37.8 & 41.0 \\
\hline \multicolumn{4}{|l|}{ Race/ethnicity } \\
\hline Hispanic (\%) & 51.4 & 61.6 & $44.9^{a}$ \\
\hline Black (\%) & 25.5 & 22.1 & $27.7^{a}$ \\
\hline White (\%) & 23.1 & 16.3 & $27.4^{a}$ \\
\hline Hypertension (\%) & 73.5 & 68.6 & $76.5^{a}$ \\
\hline Diabetes (\%) & 21.2 & 18.8 & $22.7^{a}$ \\
\hline \multicolumn{4}{|l|}{ Cigarette smoker } \\
\hline Current (\%) & 15.5 & 12.2 & $17.6^{a}$ \\
\hline Former (\%) & 37.8 & 32.7 & $40.9 a$ \\
\hline \multicolumn{4}{|l|}{ Pipe or cigar smoker } \\
\hline Current (\%) & 2.3 & 1.5 & $2.7^{a}$ \\
\hline Former (\%) & 5.9 & 4.4 & $6.8^{a}$ \\
\hline Moderate alcohol consumption (\%) & 35.1 & 34.7 & 35.3 \\
\hline Moderate to heavy physical activity (\%) & 10.0 & 12.0 & $8.8^{a}$ \\
\hline BMI (Mean \pm SD) & $27.9 \pm 5.6$ & $28.3 \pm 5.6$ & $27.7 \pm 5.6^{a}$ \\
\hline \multicolumn{4}{|l|}{ Lipid Parameters (Mean \pm SD) } \\
\hline Total cholesterol $(N=1804)$ & $202 \pm 41$ & $200 \pm 40$ & $203 \pm 42$ \\
\hline $\operatorname{LDL}(\mathbf{N}=1804)$ & $127 \pm 37$ & $125 \pm 37$ & $128 \pm 37$ \\
\hline HDL (N = 1804) & $48 \pm 15$ & $48 \pm 15$ & $48 \pm 15$ \\
\hline Triglycerides $(N=1804)$ & $133 \pm 7 \mid$ & $135 \pm 80$ & $133 \pm 65$ \\
\hline Non-HDL $(\mathbf{N}=1804)$ & $|54 \pm 4|$ & $152 \pm 40$ & $155 \pm 42$ \\
\hline $\operatorname{Lp}(\mathrm{a})(\mathbf{N}=\mathbf{5 8 2})$ & $4 I \pm 4 I$ & $39 \pm 36$ & $43 \pm 44$ \\
\hline ApoB $(\mathrm{N}=568)$ & $113 \pm 30$ & $108 \pm 29$ & $116 \pm 30^{a}$ \\
\hline ApoA-I $(N=568)$ & $146 \pm 28$ & $147 \pm 29$ & $145 \pm 27$ \\
\hline T-CHOL:HDL (N = I804) & $4.58 \pm 1.57$ & $4.54 \pm 1.52$ & $4.60 \pm 1.61$ \\
\hline LDL:HDL $(\mathbf{N}=1804)$ & $2.92 \pm 1.24$ & $2.87 \pm 1.18$ & $2.95 \pm 1.27$ \\
\hline ApoB:ApoA-I ( $N=568)$ & $0.81 \pm 0.29$ & $0.77 \pm 0.30$ & $0.83 \pm 0.28^{a}$ \\
\hline
\end{tabular}

${ }^{a} \mathrm{P}<0.05$ vs. no plaque, $\mathrm{X}^{2}$ test for categorical variables and t-test for continuous variables

lipid-lowering medication, as the baseline data were collected prior to the publication of the ATP III guidelines.

Tables 1 and 2 show the mean \pm SD for each of the lipid parameters, stratified by plaque outcome criteria. Individuals with each plaque outcome had higher ApoB and ApoB:ApoA-I ratio than those with no plaque, and those with multiple plaques also had slightly elevated LDL.
Table 3 shows the OR and 95\% CI for the relation between each of the lipid parameters and each of the carotid plaque outcomes in the multivariate-adjusted models. Increased T-CHOL, LDL, non-HDL, ApoB, TCHOL:HDL, LDL:HDL, and ApoB:ApoA-I were associated with plaque presence, whereas HDL, triglycerides, $\operatorname{Lp}(\mathrm{a})$, and ApoA-I were not. A 1-SD increase in T-CHOL (mg/dL) was associated with a $12 \%$ increased risk of plaque. Of the total cholesterol subfractions, only LDL was an independ-

Table 2: Mean and SD of lipid parameters, stratified by carotid plaque outcomes

\begin{tabular}{|c|c|c|c|}
\hline Mean \pm SD & Multiple plaques $(\mathbf{N}=727)$ & Thickness $>1.9 \mathrm{~mm}(\mathrm{~N}=514)$ & Irregular plaque $(\mathrm{N}=2 \mathrm{I} \mathrm{I})$ \\
\hline Total cholesterol & $203 \pm 43$ & $204 \pm 41$ & $203 \pm 45$ \\
\hline LDL & $129 \pm 38 a$ & $129 \pm 36$ & $129 \pm 41$ \\
\hline HDL & $47 \pm 15$ & $48 \pm 16$ & $48 \pm 15$ \\
\hline Triglycerides & $135 \pm 67$ & $|3| \pm 60$ & $|3| \pm 65$ \\
\hline Non-HDL & $156 \pm 43$ & $155 \pm 40$ & $155 \pm 47$ \\
\hline Lp(a) & $45 \pm 45$ & $44 \pm 43$ & $40 \pm 33$ \\
\hline ApoB & $118 \pm 29 a$ & $117 \pm\left. 3\right|^{a}$ & $125 \pm 36^{a}$ \\
\hline ApoA-I & $144 \pm 28$ & $145 \pm 28$ & $143 \pm 28$ \\
\hline T-CHOL:HDL & $4.68 \pm 1.65$ & $4.59 \pm 1.60$ & $4.57 \pm 1.81$ \\
\hline LDL:HDL & $3.01 \pm 1.30$ & $2.95 \pm 1.27$ & $2.93 \pm 1.45$ \\
\hline ApoB:ApoA-I & $0.85 \pm 0.29 a$ & $0.84 \pm 0.30^{a}$ & $0.91 \pm 0.35^{a}$ \\
\hline
\end{tabular}

${ }^{a} \mathrm{p}<0.05$ vs. no plaque (t-test) 
Table 3: Association between lipid parameters and carotid plaque outcomes, adjusted for demographics and vascular risk factors ${ }^{a}$

\begin{tabular}{|c|c|c|c|c|}
\hline & \multicolumn{4}{|c|}{ OR $(95 \% \mathrm{Cl})^{b}$ vs. No plaque } \\
\hline & Plaque & Multiple plaques & Thickness $>1.9 \mathrm{~mm}$ & Irregular plaque \\
\hline Total cholesterol & $1.12(1.01-1.25)$ & $1.15(1.02-1.30)$ & I.II (0.97-I.27) & $1.08(0.9 \mid-1.28)$ \\
\hline LDL & $1.14(1.02-1.27)$ & $1.16(1.03-1.31)$ & $1.13(0.99-1.29)$ & $1.09(0.91-1.29)$ \\
\hline HDL & $0.97(0.86-1.09)$ & $0.91(0.79-1.05)$ & $0.96(0.83-1.11)$ & $1.10(0.90-1.33)$ \\
\hline Triglycerides & $0.99(0.88-1.10)$ & $1.04(0.92-1.18)$ & $1.01(0.88-1.16)$ & $0.97(0.8 \mathrm{I}-\mathrm{I} .17)$ \\
\hline Non-HDL & $1.13(1.01-1.26)$ & $1.17(1.03-1.33)$ & $1.12(0.98-1.28)$ & $1.07(0.90-1.28)$ \\
\hline Lp(a) & $1.21(0.99-1.48)$ & $1.31(1.03-1.66)$ & $1.22(0.94-1.58)$ & $1.05(0.55-1.99)$ \\
\hline ApoB & $1.29(1.03-1.60)$ & $1.29(1.00-1.66)$ & $1.35(1.04-1.75)$ & $1.56(0.95-2.56)$ \\
\hline ApoA-I & $0.85(0.70-1.05)$ & $0.76(0.60-0.97)$ & $0.80(0.63-1.03)$ & $0.83(0.48-I .4 I)$ \\
\hline T-CHOL:HDL & $1.13(1.01-1.26)$ & $1.23(1.08-1.40)$ & $1.16(1.01-1.33)$ & $1.00(0.83-1.19)$ \\
\hline LDL:HDL & $1.16(1.04-1.29)$ & $1.25(1.10-1.41)$ & $1.18(1.03-1.36)$ & $1.03(0.86-1.23)$ \\
\hline ApoB:ApoA-I & $1.35(1.08-1.69)$ & $1.49(1.15-1.94)$ & $1.41(1.08-1.84)$ & $1.46(1.06-2.01)$ \\
\hline
\end{tabular}

${ }^{a}$ age, sex, race/ethnicity, hypertension, diabetes, BMI, pack-years of cigarette smoking, pipe or cigar smoking (past/current/never), moderate alcohol use, moderate to heavy physical activity, and the change in time between lipid and plaque measurements

b) SD increase

ent predictor of plaque (OR for a 1-SD increase $=1.14)$. As triglycerides were not associated with plaque, LDL is driving the association with non-HDL (OR for a 1-SD increase in non-HDL $=1.13$ ). The LDL precursor protein ApoB was even more predictive of plaque presence than LDL (OR for a 1 -SD increase $=1.29$ ).

Although the ratios T-CHOL:HDL and LDL:HDL were positively associated with plaque, as well as the presence of multiple plaques and thick plaque, in the multivariate analyses, the ratio of precursor proteins ApoB:ApoA-I was far more predictive, with a $35 \%$ increased risk of plaque observed for a 1-SD increase in ApoB:ApoA-I.

When the models were further adjusted for lipid-lowering medication use, the conclusions remained unchanged (data not shown). Interaction terms were added to the multivariate models to examine potential effect modification by race/ethnicity, sex, and age, and no significant interactions were observed.

The relative risk estimates for T-CHOL, LDL, non-HDL, and LDL:HDL were attenuated when the outcome was restricted to irregular plaque (vs. no plaque), although the association with ApoB appeared stronger. In contrast, the lipid parameters were generally more strongly predictive when the outcome was restricted to the presence of multiple plaques. Individuals with multiple plaques had significantly elevated levels of Lp(a) and lower ApoA-I.

\section{Discussion}

The results indicate a strong relation between blood lipid levels and presence of carotid plaque in our multi-ethnic population, suggesting that blood lipids likely influence the risk of cardiovascular diseases and particularly stroke due to their effects on atherosclerotic plaque formation. Elevated LDL was independently associated with carotid plaque. However, HDL and triglycerides were not significantly associated with plaque presence after controlling for other lipid parameters and vascular risk factors. An analysis of precursor proteins supported the strength of the LDL association, as ApoB, the LDL precursor protein, was associated with an increased risk of plaque, whereas ApoA-I, the HDL precursor protein, was not. In fact, the lipid parameter most predictive of plaque presence was ApoB, and particularly the ratio ApoB:ApoA-I.

Despite the lower prevalence of carotid plaque observed among the Hispanic participants, the effect of lipid levels on plaque risk was not different among the Hispanics in comparison to the other race/ethnic groups. Therefore, we did not find evidence in support of the Hispanic paradox [25] regarding the effect of blood lipids. Further research is needed on vascular risk factors for subclinical atherosclerosis in Hispanics, as Hispanics comprise the fastest growing minority population in the United States, and it is important for clinicians to be aware of possible race/ ethnic differences in the etiology of vascular disease.

Although current clinical practices involve the measurement of T-CHOL, LDL, HDL, and triglycerides to inform treatment decisions, the results of the current study suggest that the precursor protein $\mathrm{ApoB}$ and, to a lesser extent, ApoA-I may be stronger predictors of subclinical atherosclerosis, and therefore may be helpful parameters to use in clinical practice. In fact, the ratio ApoB:ApoA-I may be the best predictor of risk of atherosclerosis and likewise the optimal measure to assess new lipid-lowering medication, as treatment regimens that lower ApoB are likely to be most effective in reducing plaque formation. 
The atherosclerotic process is very complex and involves several different mechanisms including injury in the endothelium, activation of immuno-inflammatory cells, smooth muscle cell proliferation, and influx of lipoproteins through the vessel injury space $[26,27]$. The results of the current study do not suggest that HDL is unrelated to carotid plaque presence. Rather, they indicate that it is the relative levels of LDL and HDL that may be more predictive than either LDL or HDL alone, and that the HDL precursor protein ApoA-I may be more etiologically relevant than the overall HDL level. The anti-atherogenic property of HDL has been documented in both clinical observations and laboratory settings [28], as HDL has been shown to have both direct and indirect anti-inflammatory effects with potential antithrombotic results [29]. The main beneficial role of HDL is its capacity to reverse cholesterol transport, removing free cholesterol from the macrophage in the endothelium and returning it to the liver for excretion into bile, thereby protecting against atherosclerotic plaque formation [5].

The association between the ApoB:ApoA-I ratio and development of atherosclerosis [30,31] and cardiovascular disease [32] has been shown. ApoB assembles the precursor of very-low-density lipoprotein, a component of $\mathrm{LDL}$, while ApoA-I is necessary for the metabolism of HDL. Modification of the ApoB:ApoA-I ratio may affect atherosclerotic plaque development [33]. Interestingly, it has been shown that, unlike lipoproteins LDL and HDL, the apolipoproteins remain stable with age and cardiovascular disease severity [34]. We did not show that Lp(a) was independently associated with carotid plaque presence, although it was predictive of the presence of multiple plaques, and therefore may be associated with a greater plaque burden. The restricted sample of NOMAS individuals with $\mathrm{Lp}(\mathrm{a})$ measured limited the statistical power of these analyses. Data on the etiologic importance of $\mathrm{Lp}(\mathrm{a})$ has been controversial, as $\operatorname{Lp}(\mathrm{a})$ has been more related to the mechanisms of thrombosis and fibrinolysis. A recent study showed that $\operatorname{Lp}(\mathrm{a})$ was independently associated with carotid stenosis and occlusion, but not with plaque area [35]. A substudy of 426 individuals selected from the NOMAS population previously showed that maximum internal carotid artery plaque thickness was not associated with Lp(a) levels, but it was associated with the amount of Lp(a) carrying the small apo(a) size [36].

We did not find that triglycerides were associated with plaque presence after controlling for other lipid parameters and vascular risk factors. It has been shown that triglycerides are the lipid subfraction least present inside atherosclerotic plaque [37]. Furthermore, the fact that triglyceride levels vary considerably within individuals makes it more difficult to evaluate them as a risk factor for atherosclerosis. Other studies have also demonstrated no significant association between triglycerides and carotid plaque after controlling for other lipid parameters and vascular risk factors $[38,39]$.

Carotid plaque, particularly thick plaque and irregular plaque, has been shown to be a risk factor for vascular events, including stroke [23,40-42]. Because lipids likely influence the risk of CVD and stroke due to their effects on atherosclerotic plaque formation, carotid plaque may be used as a surrogate endpoint in epidemiologic and pharmacologic studies of lipid treatment.

The various lipid parameters and lipid ratios examined in our study have been shown to be predictive of combined cardiovascular events in a large population-based study of women in which the lipid parameters were not mutually adjusted for each other [1]. Interestingly, the strongest effect estimate was observed for non-HDL. This study showed that the lipid ratios were more predictive of cardiovascular disease risk than any of the individual lipid levels. However, unlike our study, the weakest association was observed for the ratio of ApoB:ApoA-I. Although lipid parameters have been well-established as predictors of coronary heart disease, their role in the pathogenesis of stroke has been more controversial. In the Atherosclerotic Risk in Communities (ARIC) study, investigators reported weak and inconsistent [nonlinear] associations between LDL, HDL, triglycerides, ApoB, and ApoA-I with ischemic stroke risk [43]. In contrast, two other large studies have demonstrated strong associations between T-CHOL and its subfractions with risk of ischemic stroke [44,45]. Lipid parameters have also been shown to be related to carotid intima-media thickness (IMT), a related yet distinct measure of subclinical atherosclerosis [34].

Studies examining the effects of lipid-lowering treatments have provided strong evidence for an important role of lipids, particularly LDL, in stroke risk. Two meta-analyses have suggested an $18 \%$ decreased risk of stroke among statin users as compared to controls $[46,47]$. The SPARCL study demonstrated a decreased risk of recurrent stroke in individuals treated with atorvastatin following a previous stroke or TIA [48]. A recent meta-analysis also suggested that the effect of statins on both stroke risk and carotid IMT progression observed across studies was closely associated with the reduction in LDL cholesterol [49].

Strengths of the current study include its large and ethnically-diverse sample population, including Hispanics, collection of information on correlated vascular risk factors necessary to estimate the independent association between lipids and carotid plaque, assessment of a range of lipid parameters, including Lp(a) which has been relatively unstudied, and the measurement of various plaque characteristics in addition to its simple presence (e.g. 
thickness, irregularity, number). However, a primary limitation is the cross-sectional nature of this study. Further research in other populations is necessary to examine the association between lipid levels ascertained longitudinally and the progression of carotid plaque, in order to better understand the temporality of the relation. In addition, information on $\mathrm{Lp}(\mathrm{a}), \mathrm{ApoB}$, and ApoA-I were available for a subsample, limiting the statistical power with which to examine these less traditional lipid parameters.

\section{Conclusions}

In conclusion, our study supports the role of total cholesterol, LDL, and particularly the precursor protein ApoB as predictors of carotid atherosclerotic plaque in a multi-ethnic population, independent of other traditional vascular risk factors. Results suggest that ApoB may be the best target for treatment in people at risk for atherosclerosis and cerebrovascular disease. The current study provides novel information on the relative utility of various lipid parameters in predicting carotid plaque, an important subclinical marker of atherosclerosis, and contributes to the growing evidence for the superior prognostic value of the apolipoproteins.

\section{Competing interests}

The authors declare that they have no competing interests.

\section{Authors' contributions}

HG performed the statistical analysis and drafted the manuscript. DM participated in the drafting of the manuscript. MSVE participated in the design of the study and helped to draft the manuscript. TR participated in the design of the study and helped to draft the manuscript. RLS conceived of the study, participated in its design, and helped to draft the manuscript. All authors read and approved the final manuscript.

\section{Acknowledgements}

This research was supported by a grant from the National Institute of Neurological Disorders and Stroke (ROI 29993).

\section{References}

I. Ridker PM, Rifai N, Cook NR, Bradwin G, Buring JE: Non-HDL cholesterol, apoliproteins A-I and $B_{100}$, standard lipid measures, lipid ratios, and CRP as risk factors for cardiovascular disease in women. JAMA 2005, 294:326-333.

2. Sacco RL, Benson RT, Kargman DE, Boden-Albala B, Tuck C, Lin IF, Cheng JF, Paik MC, Shea S, Berglund L: High-density lipoprotein cholesterol and ischemic stroke in the elderly, the Northern Manhattan Stroke Study. JAMA 200I, 285:2729-2735.

3. Law MR, Wald NJ, Rudnicka AR: Quantifying effect of statins on low density lipoprotein cholesterol, ischaemic heart disease, and stroke: systematic review and meta-analysis. $\mathrm{Br} M e d \mathrm{~J}$ 2003, 326: |423-1427.

4. Amarenco P, Bogousslavsky J, Callahan A, Goldstein LB, Hennerici M, Rudolph AE, Sillesen H, Simunovic L, Szarek M, Welch KM, Zivin JA: High-dose atorvastatin after stroke or transient ischemic attack. N Engl J Med 2006, 355:549-559.

5. Davidson MH, Toth PP: High-density lipoprotein metabolism: potential therapeutic targets. Am J Cardiol 2007, I 00:n32-40.
6. Amarenco P, Labreuche J, Touboul PJ: High-density lipoproteincholesterol and risk of stroke and carotid atherosclerosis: a systematic review. Atherosclerosis 2008, 196:489-496.

7. Subramanian R, Ramaswamy M, Wasan KM: Role of lipid and lipoprotein metabolizing enzymes in the development of atherosclerosis. Indian J Exp Biol 2003, 4I:|4-25.

8. Morrisett JD: The role of lipoprotein[a] in atherosclerosis. Curr Atheroscler Rep 2000, 2:243-250.

9. Bersano A, Ballabio E, Lanfranconi S, Mazzucco S, Candelise L, Monaco S: Statins and stroke. Curr Med Chem 2008, I 5:2380-2392.

10. LaRosa JC, Grundy SM, Waters DD, Shear C, Barter P, Fruchart JC, Gotto AM, Greten H, Kastelein JJ, Shepherd J, Wenger NK, Treating to New Targets (TNT) Investigators: Intensive lipid lowering with atorvastatin in patients with stable coronary disease. $\mathrm{N} \mathrm{Engl}$ J Med 2005, 352:1425-I435.

II. Sacco RL, Boden-Albala B, Abel G, Lin IF, Elkind M, Hauser WA, Paik $M C$, Shea S: Race-ethnic disparities in the impact of stroke risk factors: the Northern Manhattan stroke study. Stroke 200I, 32: $1725-173 \mid$.

12. Thornberry OTMJ: Coverage and response in random digit dialing national surveys. Proceedings of the Section on Survey Research Methods. Alexandria, VA: American Statistical Association; 1983:654-659.

13. Gentry EM, Kalsbeek WD, Hogelin GC, Jones JT, Gaines KL, Forman MR, Marks JS, Trowbridge FL: The behavioural risk factor surveys, II. Design, methods, and estimates from combined state data. Am J Prev Med 1985, I:9-14.

14. Kargman DE, Sacco RL, Boden-Albala B, Paik MC, Hauser WA, Shea $S$ : Validity of telephone interview data for vascular disease risk factors in a racially mixed urban community: the Northern Manhattan stroke study. Neuroepidemiology 1999 I 8: 174- I84

15. Friedewald WT, Levy RI, Fredrickson DS: Estimation of the concentration of low-density lipoprotein cholesterol in plasma, without use of the preparative ultracentrifuge. Clin Chem 1972, I 8:499-502.

16. Paultre F, Tuck CH, Boden-Albala B, Kargman DE, Todd E, Jones J, Paik MC, Sacco RL, Berglund L: Relation of Apo(a) size to carotid atherosclerosis in an elderly multiethnic population. Arterioscler Thromb Vasc Biol 2002, 22: |41-146.

17. Tuck $\mathrm{CH}$, Holleran S, Berglund L: Hormonal regulation of lipoprotein(a) levels: Effects of estrogen replacement therapy on lipoprotein (a) and acute phase reactants in postmenopausal women. Arterioscler Thromb Vasc Biol 1997, I 7:1822-1829.

18. Gillery P, Arthuis P, Cuperlier C, Circaud R: Rate nephelometric assay of serum lipoprotein(a). Clin Chem 1993, 39:503-508.

19. Elkind MS, Cheng J, Boden-Albala B, Paik MC, Sacco RL: Elevated white blood cell count and carotid plaque thickness: the Northern Manhattan Stroke Study. Stroke 200I, 32:842-849.

20. Desvarieux M, Demmer RT, Rundek T, Boden-Albala B, Jacobs DR Jr, Papapanou PN, Sacco RL: Relationship between periodontal disease, tooth loss and carotid artery plaque: The Oral Infections and Vascular Disease Epidemiology Study (INVEST). Stroke 2003, 34:2 I 20-2 I 25.

2I. Elkind MS, Cheng J, Boden-Albala B, Rudenk T, Thomas J, Chen $\mathrm{H}$ Rabbani LE, Sacco RL: Tumor necrosis factor receptor levels are associated with carotid atherosclerosis. Stroke 2002, 33:31-37.

22. Rundek T, Elkind MS, Pittman J, Boden-Albala B, Martin S, Humphries SE, Hank Juo SH, Sacco RL: Carotid intima-media thickness is associated with allelic variants of stromelysin-I, interleukin6, and hepatic lipase genes: The Northern Manhattan prospective cohort study. Stroke 2002, 33:|420-| 423.

23. Rundek T, Arif H, Boden-Albala B, Elkind MS, Paik MC, Sacco RL: Carotid plaque, a subclinical precursor of vascular events: the Northern Manhattan Study. Neurology 2008, 70:1200-1207.

24. Sacco RL, Gan R, Boden-Albala B, Lin IF, Kargman DE, Hauser WA, Shea S, Paik MC: Leisure-time physical activity and ischemic stroke risk: The Northern Manhattan Stroke Study. Stroke 1998, 29:380-387.

25. Lerman-Garber I, Villa AR, Caballero E: Diabetes and cardiovascular disease. Is there a true Hispanic paradox? Rev Invest Clin 2004, 56:282-296.

26. Hansson GK: Immune mechanisms in atherosclerosis. Arterioscler Thromb Vasc Biol 2001, 2 I: 1876-1890. 
27. Berliner JA, Navab M, Fogelman AM, Frank JS, Demer LL, Edwards PA, Watson AD, Lusis AJ: Atherosclerosis: basic mechanisms. Oxidation, inflammation, and genetics. Circulation 1995 9I:2488-2496.

28. Mineo C, Deguchi H, Griffin JH, Shaul PW: Endothelial and antithrombotic actions of HDL. Circ Res 2006, 98: I352-I 364

29. Barter PJ, Nicholls S, Raye KA, Anatharamaiah GM, Navab M, Fogelman AM: Antiinflammatory properties of HDL. Circ Res 2004, 95:764-772.

30. Panayiotou A, Griffin M, Georgiou N, Bond D, Tyllis T, Tziakouri-Shiakalli C, Fessas C, Nicolaides A: ApoB/ApoAl ratio and subclinical atherosclerosis. Int Angiol 2008, 27:74-80.

31. Junyent M, Zambón D, Gilabert R, Cofán M, Núñez I, Ros E: Carotid atherosclerosis in familial combined hyperlipidemia associated with the APOB/APOA-I ratio. Atherosclerosis 2008 197:740-746.

32. Walldius G, Jungner I: The apoB/apoA-I ratio: a strong, new risk factor for cardiovascular disease and a target for lipid-lowering therapy - a review of the evidence. J Intern Med 2006, 259:493-519.

33. Olofsson SO, Wiklund O, Borén J: Apolipoproteins A-I and B: biosynthesis, role in the development of atherosclerosis and targets for intervention against cardiovascular disease. Vasc Health Risk Manag 2007, 3:49I-502.

34. Frontini MG, Srinivasan SR, Xu JH, Tang R, Bond MG, Berenson G: Utility of non-high-density lipoprotein cholesterol versus other lipoprotein measures in detecting subclinical atherosclerosis in young adults (The Bogalusa Heart Study). Am J Cardiol 2007, 100:64-68.

35. Klein JH, Hegele RA, Hackam DG, Koschinsky ML, Huff MW, Spence JD: Lipoprotein(a) is associated differentially with carotid stenosis, occlusion, and total plaque area. Arterioscler Thromb Vasc Biol 2008, 28:185I-I856.

36. Paultre $F$, Tuck $\mathrm{CH}$, Boden-Albala B, Kargman DE, Todd $\mathrm{E}$, Jones Paik MC, Sacco RL, Berglund L: Relation of Apo(a) size to carotid atherosclerosis in an elderly multiethnic population. Arterioscler Thromb Vasc Biol 2002, 22:141-146.

37. Marinello E, Setacci C, Giubbolini M, Cinci G, Frosi B, Porcelli B, Terzuoli L: Lipid composition in atheromatous plaque: evaluation of the lipid three-phase percentage. Life Sci 2003, 72:2689-2694.

38. Kerenyi L, Mihalka L, Csiba L, Bacso H, Bereczki D: Role of hyperlipidemia in atherosclerotic plaque formation in the internal carotid artery. I Clin Ultrasound 2006, 34:283-288.

39. Sutton-Tyrrell K, Lassila HC, Meilahn E, Bunker C, Matthews KA, Kuller LH: Carotid atherosclerosis in premenopausal and postmenopausal women and its association with risk factors measured after menopause. Stroke 1998, 29: III6-II2I.

40. Prati P, Tosetto A, Vanuzzo D, Bader G, Casaroli M, Canciani L, Castellani S, Touboul PJ: Carotid intima media thickness and plaques can predict the occurrence of ischemic cerebrovascular events. Stroke 2008, 39:2470-2476.

4I. Lee EJ, Kim HJ, Bae JM, Kim JC, Han HJ, Park CS, Park NH, Kim MS Ryu JA: Relevance of common carotid intima-media thickness and carotid plaque as risk factors for ischemic stroke in patients with type 2 diabetes mellitus. Am J Neuroradiol 2007 28:916-919.

42. Prabhakaran S, Rundek T, Ramas R, Elkind MS, Paik MC, Boden-Albala $B$, Sacco RL: Carotid plaque surface irregularity predicts ischemic stroke: the northern Manhattan study. Stroke 2006 37:2696-270I

43. Shahar E, Chambless LE, Rosamond WD, Boland LL, Ballantyne CM McGovern PG, Sharrett AR: Atherosclerosis Risk in Communities Study. Plasma lipid profile and incident ischemic stroke: the Atherosclerosis Risk in Communities (ARIC) study. Stroke 2003, 34:623-631.

44. Kurth T, Everett BM, Buring JE, Kase CS, Ridker PM, Gaziano JM: Lipid levels and the risk of ischemic stroke in women. Neurology 2007, 68:556-562.

45. Tirschwell DL, Smith NL, Heckbert SR, Lemaitre RN, Longstreth WT Ir, Psaty BM: Association of cholesterol with stroke risk varies in stroke subtypes and patient subgroups. Neurology 2004 63: $1868-1875$

46. Briel M, Studer M, Glass TR, Bucher HC: Effects of statins on stroke prevention in patients with and without coronary heart disease: a meta-analysis of randomized controlled trials. Am J Med 2004, I I 7:596-606.
47. Cheung BM, Lauder IJ, Lau CP, Kumana CR: Meta-analysis of large randomized controlled trials to evaluate the impact of statins on cardiovascular outcomes. Br J Clin Pharmacol 2004, 57:640-65।.

48. Amarenco P, Bogousslavsky J, Callahan A, Goldstein LB, Hennerici M, Rudolph AE, Sillesen H, Simunovic L, Szarek M, Welch KM, Zivin JA High-dose atorvastatin after stroke or transient ischemic attack Stroke Prevention by Aggressive Reduction in Cholesterol Levels (SPARCL) Investigators. N Engl J Med 2006, I(355):549-559.

49. Amarenco P, Labreuche J, Lavallée P, Touboul PJ: Statins in stroke prevention and carotid atherosclerosis: systematic review and up-to-date meta-analysis. Stroke 2004, 35:2902-2909.

\section{Pre-publication history}

The pre-publication history for this paper can be accessed here:

http://www.biomedcentral.com/1471-2261/9/55/prepub
Publish with Bio Med Central and every scientist can read your work free of charge

"BioMed Central will be the most significant development for disseminating the results of biomedical research in our lifetime. "

Sir Paul Nurse, Cancer Research UK

Your research papers will be:

- available free of charge to the entire biomedical community

- peer reviewed and published immediately upon acceptance

- cited in PubMed and archived on PubMed Central

- yours - you keep the copyright
BioMedcentral 